\title{
World Mental Health Day: Steer away from the Detrimental
}

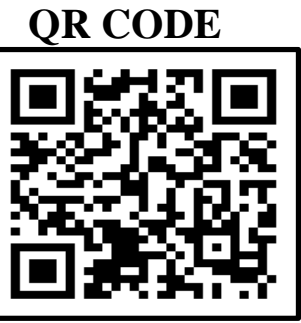

According to the World Health Organization (WHO), mental health is "a state of well-being in which the individual realizes his or her own abilities, can cope with the normal stresses of life, can work productively and fruitfully, and is able to make a contribution to his or her community." It is the state of emotional wellbeing by the virtue of which an individual is in harmony with himself and the society.

Various factors such as any mental disorders/conditions, childhood trauma, loss of a family member, financial troubles, drug abuse etc can undermine a person's psychological balance and bring about a negative effect in the overall development of the individual. $^{2}$

According to a study in which World Mental Health (WMH) surveys were conducted across 17 countries in 2007, more than $50 \%$ individuals are suffering from a mental disorder at a given point of their life. ${ }^{3}$

There is a pertinent association between physical and mental health. Patients who suffer from a chronic mental illness are at an increased risk of physical health disorders such as Diabetes Mellitus, Hypertension, Psychosomatic disorders. Similarly, chronic health diseases such as Coronary Artery Disease (CAD) or a malignancy can lead to long standing stress. ${ }^{4}$

Mental health and mental illness are two distinct terms which are often confused with each other. According to the CDC, mental illness refers to "conditions that affect a person's thinking, feeling, mood, or behaviour" whereas mental health, as mentioned above, is an individual's emotional and psychological state of wellbeing. ${ }^{5}$

Recently, COVID-19 has had a major negative impact on every individual's emotional and psychological state. This deadly disease has proved to be detrimental for the mental health for every person across the whole world. It has led to depression, anxiety and even suicides, especially in the phase of lockdown. 6 According to a pilot study in India in 2021, 151 COVID-19 related suicide reports were retrieved during various lockdown phases. Out of those, $95 \%$ of the individuals were under mental stress. ${ }^{7}$

For the World Mental Health Day (WHMD) 2021 on 1oth October, WHO has initiated a campaign with the slogan "Mental health care for all: let's make it a reality" keeping in mind the COVID-19 pandemic and improvements that can be made for healthcare workers (HCWs), students, frontline workers etc. ${ }^{8}$

It is of paramount importance that all individuals must put an effort towards creating a perfect environment for their mind. The well-known traditional methods such as connecting to near and dear ones, exercise, practicing empathy, mindfulness or meditation, avoiding use of drugs and alcohol can instil a sense of positivity in a person and enhance the mental wellbeing. After all, the established phrase "A sound mind in a sound body" can be put to use.

\section{REFERENCES}

1. World Health Organization. Promoting mental health: concepts, emerging evidence, practice (Summary Report) Geneva: World Health Organization; 2004.

2. Prince M, Patel V, Saxena S, Maj M, Maselko J, Phillips MR, Rahman A. No health without mental health. Lancet. 2007;370(9590):859-77. https://doi.org/10.1016/So14o-6736(o7)61238-o.

3. Kessler RC, Angermeyer M, Anthony JC, et al. Lifetime prevalence and age-of-onset distributions of mental disorders in the World Health Organization's World Mental Health Survey Initiative. World Psychiatry. 2007;6(3):168-76

4. Chronic Illness \& Mental Health. Bethesda, MD: 
National Institutes of Health, National Institute of Mental Health. 2015.

5. US Department of Health and Human Services. Mental health: a report of the Surgeon General. Rockville, MD: US Department of Health and Human Services, Substance Abuse and Mental Health Services Administration, Center for Mental Health Services, National Institutes of Health, National Institute of Mental Health; 1999

6. Czeisler MÉ, Lane RI, Petrosky E, Wiley JF, Christensen A, Njai R, Weavere MD, et al. Mental Health, Substance Use, and Suicidal Ideation During the COVID-19 Pandemic — United States, June 24-30,
2020. MMWR Morb Mortal Wkly Rep. 2020;69:1049-57. http://dx.doi.org/10.15585/mmwr.mm6932a1.

7. Panigrahi M, Pattnaik JI, Padhy SK, Menon V, Patra S, Rina K, et al. COVID-19 and suicides in India: A pilot study of reports in the media and scientific literature. Asian J Psychiatr. 2021;57:102560. https://doi.org/10.1016/j.ajp.2021.10256o

8. WHO. World Mental Health Day 2021; Mental health care for all: let's make it a reality (Online Article). Available from: https://www.who.int/campaigns/world-mental-health-

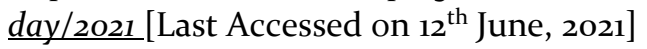

Cite this article as:

Uppal MK. World Mental Health Day: Steer away from the Detrimental. Int Healthc Res J. 2021;5(6):SC5-SC6. https://doi.org/10.26440/IHRJ/0506.09460

\section{AUTHOR AFFILIATIONS: (*Corresponding Author)}

1. Sr. Lecturer, Dept of Oral Medicine and Radiology, I.T.S Dental College, Hospital and Research Centre, Greater Noida, U.P-2013o8 (https://orcid.org/oooo-0oo2-7168-8442) 